\title{
Implantação e alcance do Serviço de Psicologia Hospitalar: um caso
}

\author{
Gláucia Faria da Silva ${ }^{1}$
}

\section{Resumo:}

O objetivo deste trabalho é apresentar os princípios norteadores da implantação do serviço de Psicologia Hospitalar do Hospital Infantil Sabará. A partir da técnica psicanalítica de construção de caso, será apresentado um exemplo concreto, visando refletir sobre o alcance da intervenção singular e multiprofissional desta proposta. O texto apresenta ainda uma breve discussão sobre a idealização da infância na contemporaneidade e a perspectiva do adoecimento como perda de lugar (DUNKER, 2011).

\section{Palavras-chave:}

Psicologia hospitalar, Psicanálise, Saúde infantil.

Hospital Psychology, Psychoanalysis, Child health.

Silva, Gláucia Faria. "Implantação e alcance do Serviço de Psicologia Hospitalar: um caso", in

\section{Anais do 2‥ Congresso Internacional Sabará de Especialidades Pediátricas}

\section{O adoecimento da infância}

Seria possível pensar em um “adoecimento da infância”? A estranha da locução se serve do termo adoecimento como DUNKER (2011) o utiliza, visando compreender o adoecimento como experiência de “perda de um lugar”, como se verá adiante. Travestida em preocupação generalizada, a infância tem sido alvo de convocações de toda ordem, o infans tem sido chamado à cena e este novo lugar de “crianças públicas” (KUPFER, LAJONQUIÈRE e VOLTOLINI, 2014) tem polarizado ações e intervenções, cuidado e olhares, onde mal se distinguem o que é excesso do que é

\footnotetext{
1 Psicanalista. Coordenadora do Serviço de Psicologia do Hospital Infantil Sabará. Membro do Laboratório de Psicanálise, Saúde e Instituição da USP. Mestre e Doutora em Psicologia Social pelo Instituto de Psicologia - USP. Editora assistente e membro da comissão editorial da Revista Brasileira de Psicologia Hospitalar.
} 
escassez. Estes olhares sobre a infância objetificam a criança, inoculando o nascimento do sujeito com a lógica diagnóstica de observação, controle e intervenção.

Da perspectiva da missão da instituição hospitalar, a prática de cuidado se reveste de ações sempre capazes de encobrir olhares prescritivos, que podem amplificar este investimento funcional do corpo e da infância. Já da perspectiva da demanda social, o hospital é um local privilegiado de endereçamento de uma miríade de sintomas e difuso mal-estar (FREUD, 1931). A partir deste encontro pode-se pensar: entre o que se oferece e o que se demanda, qual a leitura dos sintomas ali endereçados? Como respondemos? Quais efeitos podem ser, então, obtidos?

O jogo de forças entre os discursos vigentes em uma instituição eminentemente multiprofssional também são determinantes para as respostas que são formuladas. O antagonismo das narrativas médica ou psicológica é uma constatação que nos desafia à reflexão e à criatividade das interfaces em construções de narrativas permeáveis que acolham ciência, intuição e os sujeitos envolvidos, em uma ação transformadora.

\section{Norteadores da Implantação do Serviço de Psicologia Hospitalar}

Três questões cruciais foram esboçadas acima, a saber:

1- Relação entre a perspectiva metapsicológica do adoecimento como perda de lugar e o lugar ambivalente da infância sob um constante olhar diagnósticofuncional no mundo contemporâneo;

2- Os olhares funcionais sobre a infância se traduzem em cuidados que oscilam entre os polos do excesso e da escassez, violentos na medida em que norteados por idealizações;

3- A instituição hospitalar participa desta lógica, oferece cuidados e recebe demandas multifacetadas e responde a partir do resultado de um complexo jogo de forças.

Destas, tomaremos como foco de reflexão a segunda, a desmedida das práticas de cuidado relacionadas a um tempo onde os fundamentos da vida deveriam apenas nascer.

Nascer, portanto, é o foco de nosso breve olhar. Onde há algumas décadas vigiam costumes restritivos, quarentenas e resguardos em torno do nascimento em favor de uma espécie de cuidado, hoje se tem a visibilidade tecnológica do feto e a 
participação no parto em tempo real, tudo isso inserido em outra lógica de cuidado. Nasce o bebê, nasce também a linguagem, o olhar, o jogo simbólico, a interação e a ludicidade. Tudo ‘nasce’ e a consígnia de cuidado atual é: devemos estar atentos.

Não há novidade, medida ou juízo de valor a priori para a espetacularização da vida (DEBORD, 1997), mas há consequências. Assim, se o 'adoecimento da infância' aponta para esta época em que coexistem excesso de olhares e escassez de um olhar que testemunhe e espere o tempo das passagens do in-forme à forma, do inominável à nomeação, esta falta poderá acarretar mudanças naquilo que se espera dos nascimentos, ou seja, uma mudança na maneira como cada um se apropriará e reconhecerá no momento de emergência de sua voz e de seu lugar no mundo subjetivo e objetivo.

Coordenar a implantação do serviço de Psicologia no Hospital Infantil Sabará implicou e implica em tomar uma posição frente a este cenário. Nossa posição ética foi a de manter o foco na criança. Escolha aparentemente óbvia, mas que implica em priorizar a escuta e a intervenção sobre a criança e sua família de determinada maneira, partindo de três norteadores:

Nosso primeiro norteador é sempre o sintoma que trouxe a criança ao hospital para ali descortinar seu grito, seu chamado, sua fala, seu canto ou silêncio. O segundo norteador são as pegadas pulsionais e relacionais do lugar da criança na dinâmica familiar. O terceiro são as vozes e lugares que circulam sobre a criança na instituição. Destes três pontos se tece uma compreensão, uma construção de caso, e então uma intervenção.

A implantação, contudo, é um processo longo e diversificado, cuja teorização poderia nos afastar da complexidade cotidiana vivida entre os atores institucionais e das singularidades do caso a caso. Assim, a partir destes norteadores, da perspectiva psicanalítica e da visão de humanização que vigora no Hospital Infantil Sabará, focalizaremos uma intervenção que aponta para a potência institucional e a amplitude deste nosso posicionamento.

\section{$O$ caso de TEZ}

No enfrentamento do trabalho em um hospital infantil, com a diversidade dos sintomas corporais, a complexidade das dinâmicas familiares e imersos nas transformações do cuidado do capitalismo contemporâneo, há que se fazer trabalhar a 
teoria em todas as suas dimensões, reconhecendo seus alcances e limites. DUNKER (2011), problematizando a constituição da clínica psicanalítica, desdobra a proposta psicanalítica em três dimensões simultâneas, cada uma com um foco. A dimensão:

1. Psicoterapêutica, seu objeto se configura em torno sofrimento. Sugere passividade, espécie de um preocupar-se, cuja finalidade é o alívio do sofrimento e o restabelecimento.

2. Tratamento clínico se volta para os sintomas. Sugere certa atividade sobre a passividade no processo de sarar, de uso e exercício dos meios adequados;

3. Cura se interessa pelo padecimento gerado pela condição de estar no mundo, ou seja, pelo mal-estar inerente à natureza das relações com o outro. Nesta dimensão, a psicanálise não visa a cura ou o restabelecimento frente ao malestar, mas o cuidado. DUNKER (2011)

Nas três dimensões, resumidas ao máximo, podemos reconhecer instantâneos de diversas intervenções no hospital. Contudo, gostaríamos de salientar a ideia de restabelecimento, que nos será útil para a discussão do caso selecionado.

Estabelecer-se é estar em um lugar, ocupar uma posição, habitar um espaço. Assim, restabelecer-se significa estabelecer-se novamente, voltar ao ponto que estava estabelecido. Essa ideia liga, originariamente, o adoecer com a experiência de perda de lugar. Para a psicanálise, restabelecer-se indica uma apropriação do lugar de alguém ao qual se acrescentou a própria experiência de cura.

\section{Historial clínico}

Tez, uma menininha de quase 3 anos, sem diagnóstico médico fechado, não comia nada. A hipótese psicanalítica é que se tratava de caso de melancolia materna, onde a montagem da angústia envolvia a relação simbiótica entre mãe e filha. A partir desta hipótese, nosso foco foi forjar um lugar para o qual mãe e filha pudessem retornar ou apenas ocupar.

Tez foi parando de comer aos 6 meses de idade. Em julho/2013, com 2 anos e 6 meses, oscilava por volta dos 4 quilos. Apesar da gravidade da desnutrição e das consequências visíveis do desenvolvimento neuropsicomotor, Tez se comunicava com certa eficiência. Falava quatro ou cinco palavras (mãe era uma delas) e compreendia 
tudo o que lhe era dito. Para indicar suas vontades, meneava a cabeça positiva ou negativamente e apontava com o indicador imperativamente.

A Psicologia foi acionada quando uma faxineira viu a mãe bater na criança. Neste período, a criança fazia um apelo incessante: dizia "mãe” o dia inteiro, em um tom de agudo sofrimento, sem nada que a acalmasse. A mãe entrava em desespero. Apontava para cada detalhe do quarto e perguntava à filha: quer água? Quer o copo? Quer que eu levante? Sente? Apague a luz? Assim, ao apelo a mãe respondia com uma interminável sucessão de perguntas concretas que as extenuava e lançava em um crescente estado de desamparo e impotência. A criança, por sua vez, gritava e enroscava os dedos nos cabelos, arrancando chumaços. Se a mãe saía ela berrava, se ficava, ela gritava. Durante os poucos momentos em que conseguimos conversar, a mãe contou que não conseguia cortar os cabelos da criança. Tudo o que queriam era sair do hospital. Uma estenose esofágica impediu a cirurgia de gastrostomia e elas voltaram para casa, sem responder a nenhum dos encaminhamentos feitos na ocasião.

Em dezembro/2013, Tez voltou ao hospital. Chegou envolta em uma mantinha, junto a inúmeros pacotinhos de bolacha com os quais brinca de colocar dentro e tirar para fora de um potinho. A cena surpreende a equipe médica que até então não dava a devida importância para gravidade psíquica da situação.

Nesta época, Tez estava com cabelos curtos, seguia exigente e imperativa, ordenando com os dedinhos em riste que a mãe dormisse grudada à cama para que ela pudesse segurar seus cabelos. Cabelos que a mãe fez questão de arrumar no cabeleireiro antes de vir ao hospital...

De nós, equipe, a dupla não queria nada: só distância. A mãe era monossilábica e Tez se incomodava não apenas com a presença, na verdade nada entrava entre mãe e filha. Não podíamos olhar para ela. Ela chorava a qualquer mínima intervenção e a mãe pedia que saíssemos do quarto, todos - médicos, enfermeiros, voluntários, músicos, contadores de história, psicóloga.

Frente à impotência, uma repetição: se é verdade que nada entrava entre mãe e filha, um objeto fazia a função de ponte: os cabelos!

Este foi o único elemento capaz de desdobramentos que nos restou. Pois bem, na mudança desta chave, construiu-se nossa aposta nos cabelos e nós também nos agarramos a ele! 


\section{O Olho de Deus}

Esta aposta foi disseminada inicialmente por e-mail para gerentes e equipes de humanização. As equipes médica e de enfermagem, a princípio desconfiadas, logo perceberam a movimentação. Estavam envolvidos por volta de 30 profissionais entre músicos, voluntários, contadores de histórias e depois enfermeiros e médicos. Trabalhamos por 40 dias. O que fizemos? Havia uma prescrição para que todos os grupos de humanização entrassem com a maior frequência possível, porém sem pedir licença, sem olhar para Tez, levando qualquer produto cultural prazeroso, delicado e que estivesse ligado a cabelos, fio, tecer, rede...

Ao cabo de duas semanas, Tez suportava meia hora de música, olhava para quem entrava, antecipava, esperava pelos músicos quando os ouvia ao longe. Diversificamos seus brinquedos. Sem retirar as bolachas, oferecemos conchinhas para o infinito enigma dentro/fora. Com a equipe, a postura imperativa já não ‘colava’. A avó aproveitava, conversava - até que algo aconteceu quando duas educadoras a ensinaram a tecer o Olho de Deus. O Olho de Deus é uma mandala tecida com lã multicolorida em torno de quatro hastes de madeira.

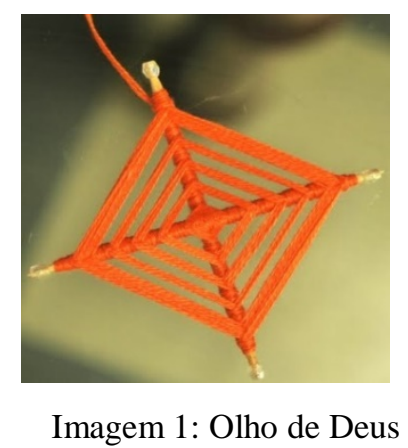

Sua origem se deve aos índios Huichol, do México. Originalmente tinha-se um tecido em que, a cada nascimento, o pai e depois outros familiares, teciam cenas que diziam sobre o passado e o futuro da criança. Quando esta história foi contada para Tez e sua avó, esta falou de um filho falecido, uma das mortes importantes mal contadas na família. Neste mesmo dia, Tez, abriu um pacotinho de suas bolachas e comeu um pedacinho. Grande confusão: ela estava de jejum e um exame importante teve que ser cancelado. Por volta de 15 dias depois desta cena, Tez teve uma complicação do quadro e faleceu.

\section{Tecendo uma rede}


A morte de Tez não muda o acontecimento e o que todos aprendemos com ele. Aprendemos que frente ao estranhamento e à recusa, é preciso encontrar uma nova perspectiva para olhar, um ponto a partir do qual começar a cuidar de outra dor.

Nossa aposta foi então tecida a partir de uma construção de caso.

A construção de caso não visa a exatidão nem a certeza. Trata-se de transmitir a lógica do caso, que não é a cronologia. A lógica de um nó, que permite observar um posicionamento subjetivo, a lógica do sintoma num dado momento, não um momento qualquer, a lógica que não pode se desfazer da transferência subjacente. BORGNIS-DESBORDES (2011)

Esta perspectiva desenhou o foco e norteou uma escolha precisa, capaz de modificar todos os olhares. Assim, tecemos, fio a fio, esta rede de proteção e oferecemos acolhimento simbólico para que mãe e filha pudessem soltar os cabelos uma da outra sem se sentirem despencar no nada.

O lugar para que as acolhêssemos começou a ser nasceu de um desejo e de um desamparo. De um primeiro momento em que uma das médicas confessou que tinha medo de Tez, lentamente construiu-se um ponto a partir do qual o estranho se tornou familiar e cada qual acolheu a seu modo a notícia de intenso desamparo que todos conhecemos.

No abismo de si encontrar o estranho (FREUD, 1919). No abismo do outro encontrar o familiar. Estas são algumas das imagens e das transferências com as quais se faz psicanálise no hospital. Este foi o laço transferencial a partir do qual apostamos naquela dupla embaraçada nas tramas de um desejo de permanecerem atadas para sempre. Apostamos no convite, nas boas-vindas, na oferta de presença-testemunho como tentativa de legitimar a dor e, a partir dela, um lugar onde houvesse um perfume de prazer.

Ecoamos os murmúrios desta dupla, para que pudessem se diferenciar de seus mortos e encontrar um lugar na ciranda da vida.

\section{Bibliografia}


BORGNIS-DESBORDES, Emmanuelle. Anotações da aula. Universidade Rennes II, Rennes, França. Primeiro semestre de 2011.

DEBORD, Guy. A sociedade do espetáculo. Rio de Janeiro: Contraponto, 1997.

DUNKER, Christian Ingo Lenz. Estrutura e Constituição da Clínica Psicanalítica: uma arqueologia das práticas de cura, psicoterapia e tratamento. São Paulo: Annablume, 2011 (Coleção Ato Psicanalítico).

FREUD, Sigmund. Lo ominoso (1919). In Obras Completas de Sigmund Freud. Buenos Aires: Amorrortu Editores, v. XVIII, 2001.

El mal-estar en la civilization (1931). In Obras Completas de Sigmund Freud. Buenos Aires: Amorrortu Editores, v. XVIII, 2001.

KUPFER, M. C. Machado; LAJONQUIÈRE, Leandro de; e VOLTOLINI, Rinaldo. Crianças públicas e adultos privados. Argumento do X Colóquio internacional do LEPSI. http://www3.fe.usp.br/secoes/inst/novo/eventos/detalhado.asp?num=1875 